\title{
Catalysis by microporous phthalocyanine and porphyrin network polymers
}

\author{
Helen J. Mackintosh, ${ }^{a}$ Peter M. Budd ${ }^{* a}$ and Neil B. McKeown ${ }^{* b}$ \\ Received 10th October 2007, Accepted 21st November 2007 \\ First published as an Advance Article on the web 10th December 2007 \\ DOI: 10.1039/b715660j
}

Cobalt phthalocyanine and iron porphyrin network polymers of intrinsic microporosity (networkPIMs) were prepared and their performance as heterogeneous catalysts compared with that of low molar mass analogues. Spiro-linked Co phthalocyanine network-PIMs prepared from preformed chlorinated phthalocyanines showed lower surface areas and lower catalytic activity than those prepared by a phthalocyanine-forming reaction from a rigid precursor incorporating a spirocentre. However, all the phthalocyanine network-PIMs were much more effective catalysts than low molar mass Co phthalocyanine for the decomposition of hydrogen peroxide, the oxidation of cyclohexene and the oxidation of hydroquinone. An Fe porphyrin network-PIM showed a higher surface area than any of the phthalocyanine polymers and showed higher activity for the oxidation of hydroquinone, also outperforming a low molar mass $\mathrm{FeCl}$ porphyrin.

\section{Introduction}

Metalloporphyrins and related compounds facilitate many important biological processes (e.g., chlorophyll for photosynthesis, hemoglobin for oxygen transport, cytochrome for electron transport, peroxidase for oxidation, catalase for hydrogen peroxide decomposition). ${ }^{1-3}$ This has prompted considerable research into porphyrins and similar aromatic macrocycles as catalysts. Phthalocyanines are more easily synthesized in high yield than porphyrins, and will form complexes with more than seventy different metal ions. ${ }^{4}$ Metallophthalocyanines are used, for example, as catalysts in the Merox process for the industrial desulfurization of petroleum. ${ }^{5-7}$ Whilst the potential of phthalocyanines and porphyrins as homogeneous catalysts has been well demonstrated, there is particular interest in incorporating the macrocycles into heterogeneous systems that offer easier recovery and recycling as well as minimizing problems of degradation and deactivation of the catalyst. Thus, they have been encapsulated in zeolites, ${ }^{8,9}$ immobilized in mesoporous materials ${ }^{10}$ and supported on polymers. ${ }^{11,12} \mathrm{~A}$ key requirement is to inhibit the tendency for the planar macrocycles to selfassociate. We therefore sought to construct network polymers incorporating phthalocyanines ${ }^{13}$ and porphyrins, ${ }^{14}$ in which the macrocycles were interlinked by rigid non-planar units, forcing them to point in different directions and creating free volume to allow access by small molecules. A spiro-centre was utilized as a site of contortion within the linker. The products are amorphous, glassy materials that exhibit high apparent surface areas $\left(500-1000 \mathrm{~m}^{2} \mathrm{~g}^{-1}\right)$ by nitrogen adsorption at $77 \mathrm{~K}$. A study of the adsorption of nitrogen and of various organic probe molecules by a spiro-linked phthalocyanine

\footnotetext{
${ }^{a}$ Organic Materials Innovation Centre, School of Chemistry, University of Manchester, Manchester, UK M13 9PL.

E-mail: Peter.Budd@manchester.ac.uk; Fax: +44 (0)161-275-4273. Tel: +44 (0)161-275-4711

${ }^{b}$ School of Chemistry, Cardiff University, Cardiff, UK CF10 3AT.

E-mail: mckeownnb@cardiff.ac.uk; Fax: +44 (0)2920-874030;

Tel: +44 (0)2920-875851
}

network polymer, and comparison with an activated carbon, demonstrated that it behaves in many respects like a microporous material as defined by $\operatorname{IUPAC}^{15}$ (i.e., possessing pores of dimensions $<2 \mathrm{~nm}$ ). ${ }^{16}$ Following on from our initial work on phthalocyanine and porphyrin network polymers, we developed a range of polymers of intrinsic microporosity (PIMs), including network polymers incorporating various catalytic centres or binding sites, and non-network, soluble polymers that can be cast to generate membranes or be processed into other useful forms. ${ }^{17-23}$

This paper describes work aimed at validating the concept that a spiro-linked phthalocyanine or porphyrin network polymer should be more effective as a heterogeneous catalyst than the low molar mass analogue. In our initial work, phthalocyanine network polymers were prepared by a phthalocyanine-forming reaction utilizing a rigid bis(phthalonitrile) precursor 3, formed from 5,5',6,6'-tetrahydroxy-3,3,3',3'tetramethyl-1,1'-spirobisindane $\mathbf{1}$ and 4,5-dichlorophthalonitrile 2 (Scheme 1). ${ }^{13}$ Porphyrin network polymers were prepared by a dibenzodioxane-forming reaction (a double aromatic nucleophilic substitution) between $\mathbf{1}$ and a preformed fluorinated porphyrin 5 (Scheme 2). ${ }^{14}$ Although the porphyrin network does not consist entirely of fused ring structures, as the phthalocyanine network does, there is sufficiently restricted rotation about the single carbon-carbon bonds at the meso positions of the porphyrin to prohibit structural relaxation of the network and maintain an open structure.

In the present work, phthalocyanine network polymers were prepared both by the initial phthalocyanine-forming route (samples CoPc-PIM-A1, CoPc-PIM-A2 and CoPc-PIM-A3) and by dibenzodioxane-forming reactions with preformed chlorinated phthalocyanines (Scheme 3) (samples CoPcPIM-B1 and CoPc-PIM-B2). Three test reactions were utilized in catalysis studies, as outlined below.

\section{Decomposition of hydrogen peroxide}

The catalase-like activity of phthalocyanines for hydrogen peroxide decomposition was identified as long ago as $1938 .^{24}$ 


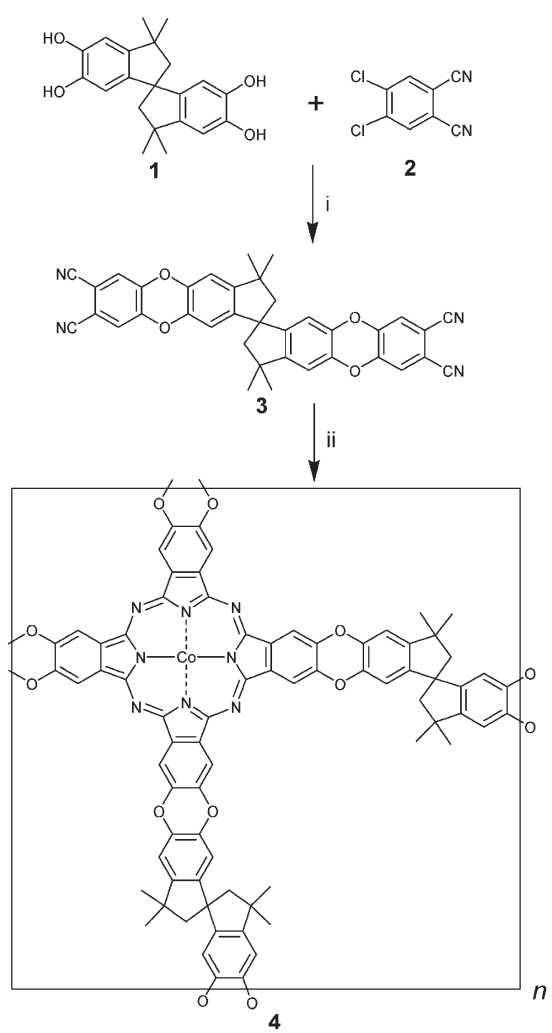

Scheme 1 Preparation of spiro-linked cobalt phthalocyanine network polymer (CoPc-PIM-A) utilizing a phthalocyanine-forming reaction. Reagents and conditions: (i) $\mathrm{K}_{2} \mathrm{CO}_{3}$, DMF, $70{ }^{\circ} \mathrm{C}$; (ii) $\mathrm{Co}\left(\mathrm{CH}_{3} \mathrm{COO}\right)_{2}$, quinoline, $220^{\circ} \mathrm{C}$.

Fe phthalocyanines are generally the most active, but Co phthalocyanines also show some activity. ${ }^{25}$ Homogeneous phthalocyanine catalysts are liable to decompose during the reaction, but the stability is improved when they are anchored to a polymer chain. ${ }^{11}$ In the present work, the performance of low molar mass Co phthalocyanine as a heterogeneous catalyst is compared with Co phthalocyanine network-PIMs prepared by different routes. A gas burette was utilized to monitor $\mathrm{O}_{2}$ evolved during $\mathrm{H}_{2} \mathrm{O}_{2}$ decomposition.

\section{Oxidation of cyclohexene}

Phthalocyanines have been widely studied as catalysts for the oxidation of alkenes with various oxidants. ${ }^{8,9,26,27}$ Here, $t$-butylhydroperoxide is used for oxidation of cyclohexene and, as above, the performance of low molar mass Co phthalocyanine as a heterogeneous catalyst is compared with Co phthalocyanine network-PIMs prepared by different routes. Gas chromatography-mass spectrometry (GC-MS) was utilised to identify and quantify the reaction products.

\section{Oxidation of hydroquinone}

Metallophthalocyanines and metalloporphyrins have been found to catalyse the oxidation of phenols to quinones by molecular oxygen under mild conditions and use has been made of this in multi-step electron transfer systems. ${ }^{28,29}$ Here, we investigate the oxidation of hydroquinone to benzoquinone and compare the performance of low molar mass $\mathrm{Co}$ and $\mathrm{Fe}$
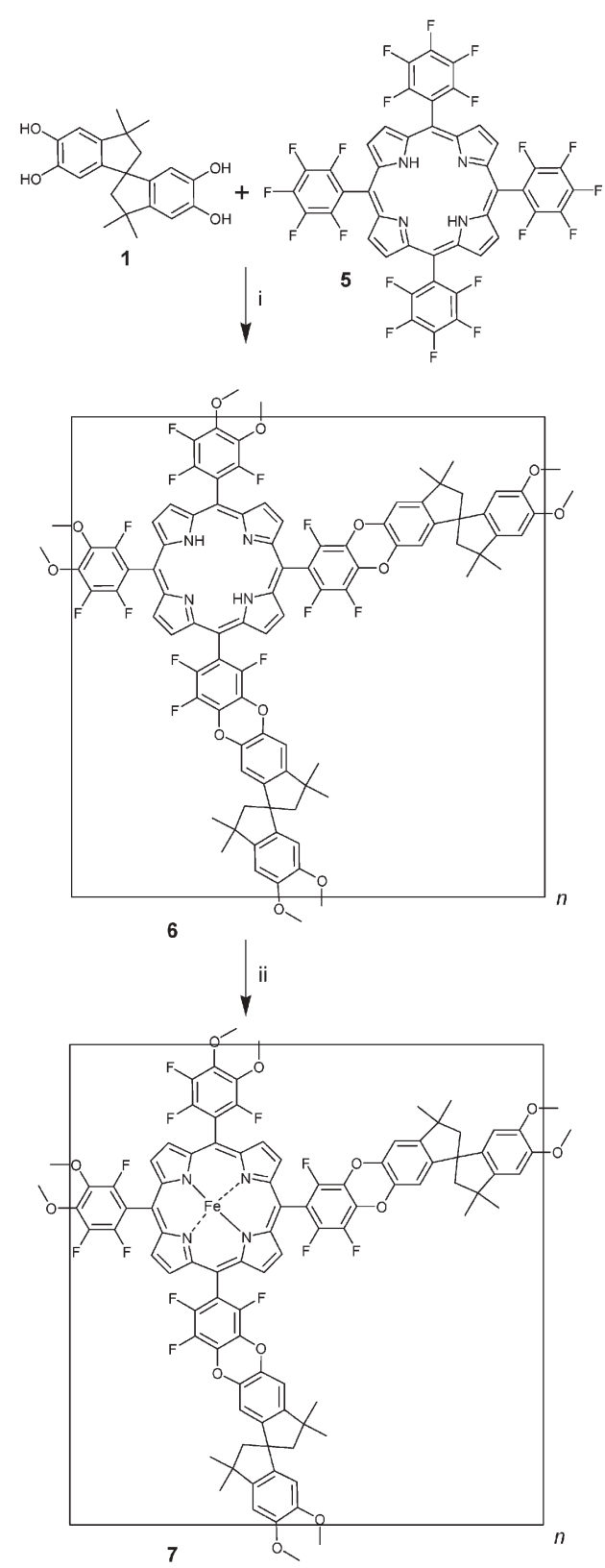

Scheme 2 Preparation of spiro-linked iron porphyrin network polymer (FePorph-PIM). Reagents and conditions: (i) $\mathrm{K}_{2} \mathrm{CO}_{3}, \mathrm{NMP}$, $170{ }^{\circ} \mathrm{C}, 5 \mathrm{~h}$; (ii) $\mathrm{FeCl}_{3}$, NMP, $120{ }^{\circ} \mathrm{C}, 24 \mathrm{~h}$.

phthalocyanines and a fluorinated $\mathrm{FeCl}$ porphyrin with a Co phthalocyanine network-PIM (CoPc-PIM-A2) and an Fe porphyrin network-PIM (FePorph-PIM). A gas burette was utilized to monitor $\mathrm{O}_{2}$ consumed during hydroquinone oxidation.

\section{Experimental}

\section{General methods}

Apparent surface areas were determined by the multi-point Brunauer-Emmitt-Teller (BET) method from nitrogen adsorption measurements at $77 \mathrm{~K}$ using a Coulter SA3100 instrument. UV-visible spectra were recorded using a Cary $1 \mathrm{E}$ 

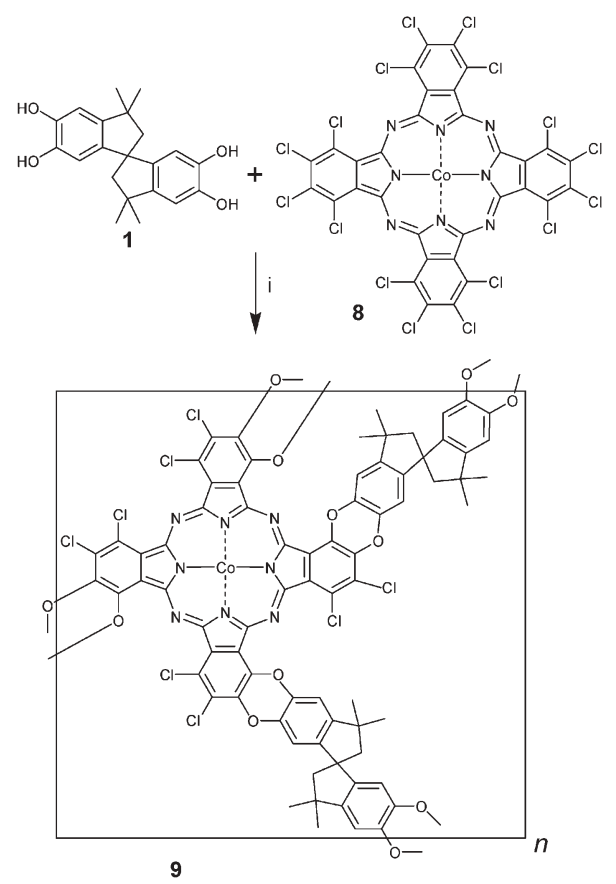

Scheme 3 Preparation of spiro-linked cobalt phthalocyanine network polymer (CoPc-PIM-B) from preformed chlorinated phthalocyanine. Reagents and conditions: (i) $\mathrm{K}_{2} \mathrm{CO}_{3}, \mathrm{NMP}, 195^{\circ} \mathrm{C}, 24 \mathrm{~h}$.

spectrometer. Analysis of $\mathrm{C}, \mathrm{H}$ and $\mathrm{N}$ was carried out with a Carlo Erba EA1101 elemental analyser, of Co and Fe with a Fisons Horizon ICP, of $\mathrm{Cl}$ (following oxygen flask combustion) with a Metrohm 686 titroprocessor and of F (following oxygen flask combustion) with a Cecil Instruments CE292 UV spectrophotometer.

\section{Co phthalocyanine polymers}

Three samples of Co phthalocyanine network-PIM (designated CoPc-PIM-A1, CoPc-PIM-A2 and CoPc-PIM-A3) were prepared by a phthalocyanine-forming reaction (Scheme 1) as described previously. ${ }^{13,16}$ Two samples of Co phthalocyanine network-PIM (designated CoPc-PIM-B1 and CoPc-PIM-B2) were prepared from a pre-formed phthalocyanine (Scheme 3) as follows: hexadecachlorophthalocyanine 8 (1 g, $0.89 \mathrm{mmol})$, spirobisindane 1 (0.61 g, $1.79 \mathrm{mmol}), \mathrm{K}_{2} \mathrm{CO}_{3}(1.40 \mathrm{~g}$, $10.14 \mathrm{mmol}$ ) and $\mathrm{N}$-methylpyrrolidone (NMP, $12 \mathrm{~cm}^{3}$ ) were stirred at $195{ }^{\circ} \mathrm{C}$ under a nitrogen atmosphere. After $24 \mathrm{~h}$ an insoluble solid precipitated from solution. The reaction mixture was cooled and a green solid was filtered off. The solid was purified by Soxhlet extraction (methanol $48 \mathrm{~h}$, tetrahydrofuran $48 \mathrm{~h}$, acetone $24 \mathrm{~h})$, refluxed in acetone $(3 \times 1 \mathrm{~h})$ and filtered off (yield 81\%). Found for CoPc-PIM-B1: C, 58.1; $\mathrm{H}, 4.1 ; \mathrm{N}, 5.0 ; \mathrm{Cl}, 19.1$; Co, 3.4\%. Calc. for $\mathrm{C}_{74} \mathrm{H}_{40} \mathrm{Cl}_{8} \mathrm{~N}_{8} \mathrm{O}_{8} \mathrm{Co}$ : C, 58.8; H, 2.6; N, 7.4; Cl, 18.8; Co, 3.9\%. $\lambda_{\max }$ (1-chloronaphthalene)/nm 678 .

\section{Fe porphyrin polymer}

A metal-free porphyrin network 6 was prepared by reaction of 1 with porphyrin $\mathbf{5}$ and the network was subsequently metallated (Scheme 2). Porphyrin 5 (0.17 g, $0.174 \mathrm{mmol}$ ), spirobisindane 1 (0.12 g, $0.348 \mathrm{mmol}), \mathrm{K}_{2} \mathrm{CO}_{3}(0.38 \mathrm{~g}$, $2.75 \mathrm{mmol})$ and anhydrous NMP $\left(4 \mathrm{~cm}^{3}\right)$ were stirred at $170{ }^{\circ} \mathrm{C}$ under a nitrogen atmosphere. After $5 \mathrm{~h}$ a solid precipitated from solution. The mixture was cooled, methanol $\left(30 \mathrm{~cm}^{3}\right)$ was added, the mixture was stirred for $30 \mathrm{~min}$, then a purple solid was filtered off. The solid was purified by Soxhlet extraction (methanol $48 \mathrm{~h}$, tetrahydrofuran $48 \mathrm{~h}$, acetone $24 \mathrm{~h}$ ), refluxed in acetone $(3 \times 1 \mathrm{~h})$ and filtered off to give 6 as a purple powder (yield 94\%). Found: C, 68.5; H, 3.1; F, 16.0; N 4.0\%. Calc. for $\mathrm{C}_{84} \mathrm{H}_{42} \mathrm{~F}_{12} \mathrm{~N}_{8} \mathrm{O}_{8}$ : C, 69.0; H, 2.9; F, 15.6; N, 3.8\%. $\lambda_{\text {max }}$ (1-chloronaphthalene)/nm 435. BET surface area $681 \mathrm{~m}^{2} \mathrm{~g}^{-1}$.

Metallation of 6: porphyrin network $6(0.13 \mathrm{~g}, 0.089 \mathrm{mmol})$, $\mathrm{Fe}^{\mathrm{III}} \mathrm{Cl}_{3}(0.15 \mathrm{~g}, 0.89 \mathrm{mmol})$ and anhydrous NMP $\left(4 \mathrm{~cm}^{3}\right)$ were stirred at $120{ }^{\circ} \mathrm{C}$ for $24 \mathrm{~h}$ under a nitrogen atmosphere. The mixture was cooled, methanol $\left(10 \mathrm{~cm}^{3}\right)$ was added, and a purple solid was filtered off. The solid was purified by Soxhlet extraction (methanol $72 \mathrm{~h}$, tetrahydrofuran $24 \mathrm{~h}$, acetone $24 \mathrm{~h}$ ), refluxed in acetone $(3 \times 1 \mathrm{~h})$ and filtered off to give 7 as a purple solid (yield 65\%). Found: C, 63.3; H, 3.5; F, 14.0; N, 3.7; Fe, 2.5\%. Calc. for $\mathrm{C}_{84} \mathrm{H}_{40} \mathrm{~F}_{12} \mathrm{~N}_{4} \mathrm{O}_{8} \mathrm{Fe}$ : C, 66.5; H, 2.6; F, $15.0 ; \mathrm{N}, 3.7 ; \mathrm{Fe}, 3.6 \%$. $\lambda_{\max }$ (1-chloronaphthalene)/nm 415.

\section{Low molar mass catalysts}

Cobalt(II) phthalocyanine (CoPc, Aldrich) was used as received. Iron(II) phthalocyanine (FePc, Aldrich) was activated as follows: FePc ( $2 \mathrm{~g}, 3.5 \mathrm{mmol})$ was dissolved in conc. $\mathrm{H}_{2} \mathrm{SO}_{4}$ $\left(50 \mathrm{~cm}^{3}\right)$, the solution was filtered and the filtrate was added to ethanol $\left(300 \mathrm{~cm}^{3}\right)$. The precipitate was separated by centrifugation and the solid was washed three times with $\mathrm{H}_{2} \mathrm{O}$, then added to $\mathrm{H}_{2} \mathrm{O}\left(30 \mathrm{~cm}^{3}\right)$ and neutralized by addition of $\mathrm{NH}_{4} \mathrm{OH}$. The active FePc was separated by centrifugation and dried (yield 96\%). 5,10,15,20-Tetrakis(pentafluorophenyl) porphyrin iron(III) chloride $\left(\mathrm{FeCl}\left(\mathrm{PhF}_{5}\right)_{4}\right.$ Porph, Aldrich) was used as received.

\section{Decomposition of hydrogen peroxide}

$\mathrm{H}_{2} \mathrm{O}_{2}$ decomposition experiments were carried out using a simple catalysis rig comprising a glass line connected via isolating taps to a round-bottomed flask, a gas burette, and a port for evacuation of the line and introduction of oxygen. A water-bath was used to control the temperature of the reaction flask. The line was first evacuated then filled with $\mathrm{O}_{2}$. Water was added to the flask and purged with $\mathrm{O}_{2}$ for $5 \mathrm{~min}$. The catalyst was added and the mixture was stirred at $30{ }^{\circ} \mathrm{C}$ for $12 \mathrm{~h} . \mathrm{H}_{2} \mathrm{O}_{2}$ was added and the reaction mixture was stirred for $3 \mathrm{~h}$. The volume of $\mathrm{O}_{2}$ in the burette was measured immediately after addition of $\mathrm{H}_{2} \mathrm{O}_{2}$, then readings of the volume of $\mathrm{O}_{2}$ evolved were taken at intervals. Initial rates of reaction were determined from quadratic fits to the experimental data for oxygen evolved as a function of time. Typical experiments were carried out with $4.78 \mathrm{~cm}^{3} \mathrm{H}_{2} \mathrm{O}$, an initial $\mathrm{H}_{2} \mathrm{O}_{2}$ concentration of $0.75 \mathrm{~mol} \mathrm{dm}^{-3}$ and a catalyst concentration corresponding to $1 \mathrm{~mol}^{\%} \mathrm{Co}$, relative to peroxide. To investigate the order of reaction, experiments were also carried out with different $\mathrm{H}_{2} \mathrm{O}_{2}$ concentrations (down to $0.19 \mathrm{~mol} \mathrm{dm}^{-3}$ ) and different catalyst concentrations $\left(1.9-7.5 \times 10^{-3} \mathrm{~mol} \mathrm{dm}^{-3}\right)$. For CoPc and CoPc-PIM-A1, the temperature dependence was also investigated, over the range $30-60{ }^{\circ} \mathrm{C}$. 


\section{Oxidation of cyclohexene}

For cyclohexene oxidation, catalyst $\left(9 \times 10^{-2} \mathrm{mmol} \mathrm{Co}\right)$ was added to a mixture of cyclohexene $\left(0.1 \mathrm{~cm}^{3}, 0.99 \mathrm{mmol}\right)$ and dichloromethane $\left(3 \mathrm{~cm}^{3}\right)$. The reaction was stirred at room temperature and $70 \% t$-butylhydroperoxide solution in water $\left(0.14 \mathrm{~cm}^{3}, 1 \mathrm{mmol}\right)$ was added. The reaction was stirred for 4 weeks. Samples $\left(0.1 \mathrm{~cm}^{3}\right)$ were removed at intervals and analysed by GC-MS using a Perkin-Elmer Autosystem XL gas chromatograph with Turbomass mass spectrometer. Chromatogram peaks were identified by comparison with those of pure compounds.

\section{Oxidation of hydroquinone}

Hydroquinone oxidation experiments were carried out using a rig similar to that described for $\mathrm{H}_{2} \mathrm{O}_{2}$ decomposition, using the gas burette in this case to measure oxygen consumed rather than oxygen evolved. Hydroquinone $(0.25 \mathrm{~g}, 2.27 \mathrm{mmol})$ was dissolved in glacial acetic acid $\left(5 \mathrm{~cm}^{3}\right)$ in the reaction vessel.

The line was evacuated, then oxygen was added to the line and burette. Finely ground catalyst (corresponding to $1 \mathrm{~mol} \%$ metal, relative to hydroquinone) was added to the reaction vessel, the tap to the line was opened and the volume of oxygen in the burette was immediately measured. The reaction was stirred for $8 \mathrm{~h}$ and readings of the volume of $\mathrm{O}_{2}$ consumed were taken at intervals.

\section{Results and discussion}

\section{Polymer catalysts}

Apparent surface areas and metal contents for the polymer catalysts utilized in this study are listed in Table 1. The properties depend critically on the purity of monomers and the efficacy of purification of the product, so the same procedure can give products with a range of surface areas. However, substantially lower surface areas were obtained for Co phthalocyanine polymers prepared using preformed phthalocyanine (CoPC-PIM-B1, B2) than for those prepared by the phthalocyanine-forming route (CoPc-PIM-A1, A2, A3), reflecting differences in molecular structure and the potential for association of macrocycles to occur during synthesis. A higher surface area was achieved for the porphyrin networkPIM than for the phthalocyanine polymers. It should be noted that surface area is only a crude indication of the effective porosity of polymers like these. Their properties depend critically on how the porosity (free volume) is distributed within the material. Techniques for properly evaluating effective micropore distributions are the subject of ongoing research.

Table 1 BET surface area, $S_{\mathrm{BET}}$, and metal content for polymer catalysts

\begin{tabular}{lll}
\hline Polymer & $S_{\mathrm{BET}} / \mathrm{m}^{2} \mathrm{~g}^{-1}$ & Metal content $(\%)$ \\
\hline CoPc-PIM-A1 & 612 & 5.8 \\
CoPc-PIM-A2 & 453 & 4.0 \\
CoPc-PIM-A3 & 494 & 3.0 \\
CoPc-PIM-B1 & 201 & 3.4 \\
CoPc-PIM-B2 & 120 & 4.8 \\
FePorph-PIM & 866 & 3.6
\end{tabular}

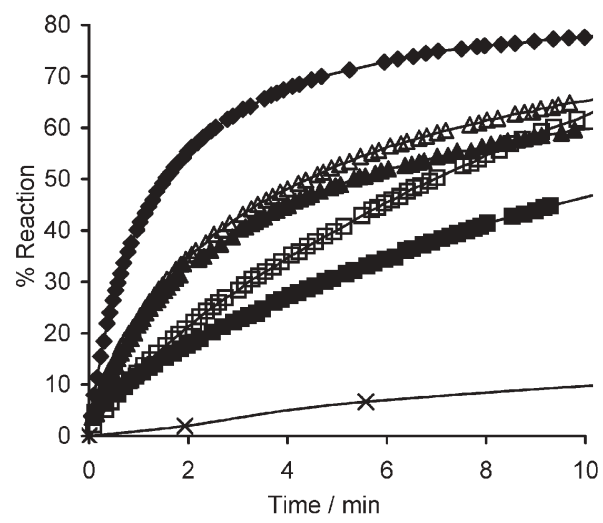

Fig. 1 Typical plots of percentage reaction as a function of time for decomposition of $\mathrm{H}_{2} \mathrm{O}_{2}$ with $(\triangle)$ CoPc-PIM-A1, ( $\Delta$ ) CoPc-PIM-A2, $(\diamond)$ CoPc-PIM-A3, ( $\square$ ) CoPc-PIM-B1, ( $\square$ ) CoPc-PIM-B2 and (x) CoPc.

\section{Decomposition of hydrogen peroxide}

Results of typical $\mathrm{H}_{2} \mathrm{O}_{2}$ decomposition experiments are shown in Fig. 1 for each of the Co phthalocyanine network-PIMs and for low molar mass Co phthalocyanine $(\mathrm{CoPc})$. None of the catalysts are soluble in the reaction medium and so all are functioning as heterogeneous catalysts. With $\mathrm{CoPc}$, for which accessibility of reagents to the catalytic centre will be restricted due to strong association of macrocycles, the reaction is slow. All the Co phthalocyanine network-PIMs tested show a substantial enhancement of reaction rate. This is quantified in Table 2, which gives initial rates of reaction (average for 3-8 runs) for each catalyst. Experiments carried out with different catalyst concentrations and different $\mathrm{H}_{2} \mathrm{O}_{2}$ concentrations indicated that, over the range of conditions investigated, the reaction is first order in catalyst concentration [cat] and first order in peroxide concentration $\left[\mathrm{H}_{2} \mathrm{O}_{2}\right]$, i.e. rate $=k[$ cat $]\left[\mathrm{H}_{2} \mathrm{O}_{2}\right]$. Values of the second order rate constant $k$ are given in Table 2. The best performing network polymer (CoPc-PIM-A3) shows two orders of magnitude increase in rate constant compared to the low molar mass analogue. Even the network-PIMs prepared from preformed phthalocyanine (CoPc-PIM-B1, B2), which have relatively low surface areas, show more than an order of magnitude increase in rate constant. For CoPc and CoPc-PIM-A1, Arrhenius plots of data obtained at various temperatures gave apparent activation energies of $65 \mathrm{~kJ} \mathrm{~mol}^{-1}$ and $16 \mathrm{~kJ} \mathrm{~mol}^{-1}$, respectively.

Table 2 Initial rate, $v$, and rate constant, $k$, for decomposition of $\mathrm{H}_{2} \mathrm{O}_{2}$ with Co phthalocyanine catalysts

\begin{tabular}{lll}
\hline Catalyst & $v^{a} / \mathrm{mol}_{-} \mathrm{O}_{2} \mathrm{~mol}_{-\mathrm{cat}^{-1} \mathrm{~h}^{-1}}$ & $k / 10^{-3} \mathrm{dm}^{3} \mathrm{~mol}^{-1} \mathrm{~s}^{-1}$ \\
\hline CoPc & $17.7 \pm 1.3$ & 0.033 \\
CoPc-PIM-A1 & $620 \pm 52$ & 1.2 \\
CoPc-PIM-A2 & $725 \pm 39$ & 1.3 \\
CoPc-PIM-A3 & $1845 \pm 163$ & 3.4 \\
CoPc-PIM-B1 & $349 \pm 29$ & 0.65 \\
CoPc-PIM-B2 & $287 \pm 6$ & 0.53
\end{tabular}

${ }^{a}$ Initial rate values quoted are the mean for at least three runs \pm the standard error of the mean. 
Table 3 Percentage composition of the reaction mixture at $8 \mathrm{~h}$ and 4 weeks for the oxidation of cyclohexene $\left(0.33 \mathrm{~mol} \mathrm{dm}^{-3}\right)$ in dichloromethane by $t$-butylhydroperoxide with $\mathrm{Co}$ phthalocyanine catalysts $\left(0.03 \mathrm{~mol} \mathrm{Co} \mathrm{dm}^{-3}\right)$

\begin{tabular}{llrrrr}
\hline \multirow{2}{*}{ Catalyst } & Time & & & \\
CoPc & $8 \mathrm{~h}$ & 91 & 1 & 2 & 6 \\
& 4 weeks & 83 & 1 & 5 & 11 \\
CoPc-PIM-A2 & $8 \mathrm{~h}$ & 43 & 5 & 7 & 45 \\
& 4 weeks & 1 & 9 & 12 & 78 \\
CoPc-PIM-B2 & 8 h & 54 & 5 & 7 & 34 \\
& 4 weeks & 2 & 11 & 15 & 72 \\
\hline
\end{tabular}

\section{Oxidation of cyclohexene}

Cyclohexene oxidation by $t$-butylhydroperoxide with Co phthalocyanine catalysts yields a mixture of three products: cyclohexene oxide, cyclohexene-2-ol and 2-cyclohexene-1-one. The composition of the reaction mixture after $8 \mathrm{~h}$ and 4 weeks is shown in Table 3 for experiments carried out with low molar mass $\mathrm{CoPc}$ and with network-PIMs CoPc-PIM-A2 and CoPc-PIM-B2. In each case, the major product is 2-cyclohexene-1-one, the yield of which is shown as a function of time in Fig. 2. In these experiments, all the catalysts are insoluble in the reaction mixture. As was found in the decomposition of $\mathrm{H}_{2} \mathrm{O}_{2}$, the $\mathrm{Co}$ phthalocyanine networkPIMs show substantially enhanced catalytic activity relative to the low molar mass analogue. After four weeks, for CoPcPIM-A2 the total product yield is $99 \%$, whilst for CoPc it is just $17 \%$.

It is of interest to compare the results obtained here with data reported by Sehlotho and Nyokong ${ }^{26}$ for cyclohexene oxidation catalysed by $\mathrm{CoPc}$ and iron percholorophthalocyanine $\left(\mathrm{FeCl}_{16} \mathrm{Pc}\right)$. Their experiments differ from the present work in that a solvent mixture (DMF : dichloromethane $3: 7$ ) was employed in which the catalysts were soluble, so they were dealing with a homogeneous system. For each product, the selectivity (yield as a percentage of the total yield for all products) after $8 \mathrm{~h}$ is given in Table 4.

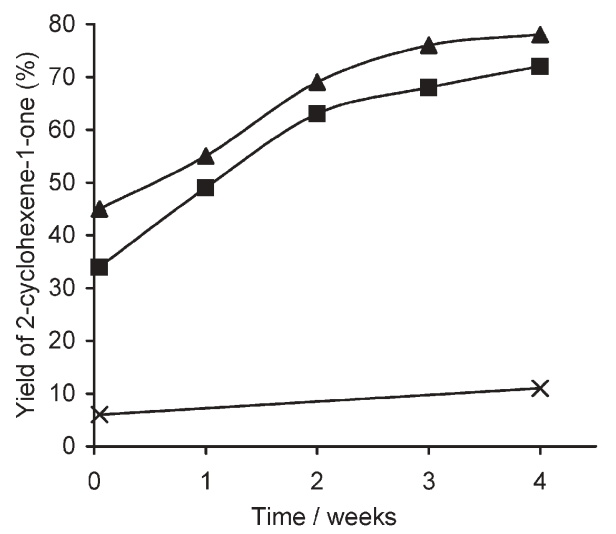

Fig. 2 Percentage yield of 2-cyclohexene-1-one as a function of time for oxidation of cyclohexene by $t$-butylhydroperoxide with $(\mathbf{A}) \mathrm{CoPc}$ PIM-A2, ( $)$ CoPc-PIM-B2 and $(\times)$ CoPc.
Table 4 Selectivity to product after $8 \mathrm{~h}$ for the oxidation of cyclohexene by $t$-butylhydroperoxide with phthalocyanine catalysts

\begin{tabular}{llrrrr}
\hline Catalyst & Nature & & & \\
\hline $\mathrm{CoCl}_{16} \mathrm{Pc}$ & Homogeneous & 8 & 20 & 72 & 26 \\
$\mathrm{CoPc}$ & Homogeneous & 6 & 34 & 61 & 26 \\
$\mathrm{CoPc}$ & Heterogeneous & 11 & 22 & 67 & This work \\
$\mathrm{CoPc-PIM}-\mathrm{A} 2$ & Heterogeneous & 9 & 12 & 79 & This work \\
CoPc-PIM-B2 & Heterogeneous & 11 & 15 & 74 & This work \\
\hline
\end{tabular}

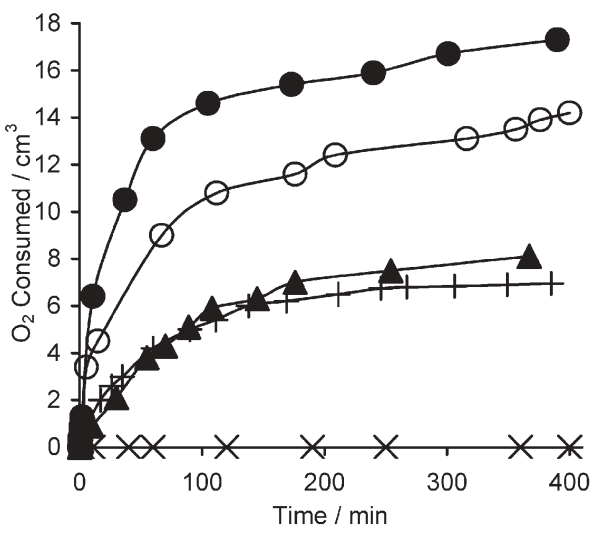

Fig. 3 Oxygen consumed as a function of time for oxidation of hydroquinone with $(\boldsymbol{\Delta})$ CoPc-PIM-A2, $(\times) \mathrm{CoPc},(+) \mathrm{FePc}$, FePorph-PIM and $(\bigcirc) \mathrm{FeCl}\left(\mathrm{Ph}_{5}\right)_{4}$ Porph.

\section{Oxidation of hydroquinone}

Plots of oxygen consumed over time are shown in Fig. 3 for the oxidation of hydroquinone with various catalysts. Initial rates derived from data for the first two minutes of reaction are listed in Table 5, along with turnover numbers (TON) after $4 \mathrm{~h}$. Values are based on the assumption that all metal centres are active, whereas in reality, of course, some may be inaccessible because of structural defects or mass transfer effects. Table 5 also includes results from Zsigmond et al. ${ }^{29}$ for $\mathrm{CoPc}, \mathrm{FePc}$ and $\mathrm{CoPc}$ encapsulated in zeolite $\mathrm{Y}$ (CoPc-ZeY). $\mathrm{CoPc}$ is soluble in the reaction solvent (acetic acid), creating a homogeneous system. However, as has been observed previously, ${ }^{29} \mathrm{CoPc}$ has no catalytic activity, perhaps because of dimerization and/or degradation in solution. In contrast, the

Table 5 Initial rate, $v$, and turnover number (TON) after $4 \mathrm{~h}$ for the oxidation of hydroquinone by molecular oxygen with phthalocyanine and porphyrin catalysts

\begin{tabular}{llll}
\hline Catalyst & $\begin{array}{l}v / \mathrm{mol}_{2} \mathrm{O}_{2} \\
\text { mol-cat }^{-1} \mathrm{~h}^{-1}\end{array}$ & $\begin{array}{l}\text { TON } \\
\text { after } 4 \mathrm{~h}\end{array}$ & Ref. \\
\hline CoPc & 0 & - & This work \\
FePc & 0 & - & 29 \\
& 7.3 & 12 & This work \\
CoPc-PIM-A2 & 9.7 & 16 & 29 \\
CoPc-ZeY & 33 & 13 & This work \\
FeCl(PhF $)_{4}$ Porph & 10.4 & 6 & 29 \\
FePorph-PIM & 43 & 23 & This work \\
& 64 & 28 & This work \\
& & &
\end{tabular}


Co phthalocyanine network polymer CoPc-PIM-A2 shows significant activity, with a higher initial rate than for FePc which had been activated by precipitation from sulfuric acid. For FePc, the initial rate and TON obtained in this work are a little lower than the values reported by Zsigmond et al. ${ }^{29}$ but CoPc-PIM-A2 shows significantly improved performance compared to the data reported for $\mathrm{CoPc}$ encapsulated in zeolite Y.

The low molar mass porphyrin catalyst, $\mathrm{FeCl}\left(\mathrm{PhF}_{5}\right)_{4} \mathrm{Porph}$, shows higher activity than any of the phthalocyanine catalysts, but this is exceeded by the Fe porphyrin network polymer (FePorph-PIM). Once again, this demonstrates improved performance by a network-PIM as compared to a low molar mass analogue.

\section{Conclusions}

Incorporation of Co phthalocyanine units into microporous, spiro-linked polymer networks with apparent surface areas in the range $120-612 \mathrm{~m}^{2} \mathrm{~g}^{-1}$ gives materials which show considerably enhanced catalytic activity, compared to the low molar mass analogue, for $\mathrm{H}_{2} \mathrm{O}_{2}$ decomposition, cyclohexene oxidation and hydroquinone oxidation. Similarly, a microporous, spiro-linked Fe porphyrin polymer network of high surface area $\left(866 \mathrm{~m}^{2} \mathrm{~g}^{-1}\right)$ shows enhanced catalytic activity for hydroquinone oxidation. These materials may be regarded as simple biomimetic systems, in which the rigid spiro-linked network creates space around the active centres, enabling reagents to gain access and reaction to occur. The results demonstrate the considerable potential for heterogeneous catalysis of network polymers of intrinsic microporosity (PIMs) incorporating catalytically active units.

\section{Acknowledgements}

We thank Dr Carin E. Tattershall for synthesizing polymers CoPc-PIM-A1 and CoPc-PIM-A2 and Dr A. Verena Maffei for synthesizing polymer CoPc-PIM-A3. We thank EPSRC and the Institute of Applied Catalysis for financial support.

\section{References}

1 J. E. Falk and K. M. Smith, Porphyrins and Metalloporphyrins, Elsevier, Amsterdam, 1975.

2 D. Dolphin, The Porphyrins, Academic, New York, 1979.
3 B. Grimm, R. J. Porra, W. Ruediger and H. Scheer, Chlorophylls and Bacteriochlorophylls: Biochemistry, Biophysics, Functions and Applications, Springer, Dordrecht, 2006.

4 N. B. McKeown, Phthalocyanine Materials: Synthesis, Structure and Function, Cambridge University Press, Cambridge, 1998.

5 W. M. Brouwer, P. A. M. Traa, T. J. W. De Weerd, P. Piet and A. L. German, Angew. Makromol. Chem., 1984, 128, 133-147.

6 A. Leitao, C. Costa and A. Rodrigues, Chem. Eng. Sci., 1987, 42, 2291-2299.

7 H. Fischer, G. Schulz-Ekloff, T. Buck, D. Woehrle, M. Vassileva and A. Andreev, Langmuir, 1992, 8, 2720-2723.

8 E. Paez-Mozo, N. Gabriunas, R. Maggi, D. Acosta, P. Ruiz and B. Delmon, J. Mol. Catal., 1994, 91, 251-258.

9 K. J. Balkus, Jr., M. Eissa and R. Levado, J. Am. Chem. Soc., 1995, 117, 10753-10754.

10 P. Karandikar, A. J. Chandwadkar, M. Agashe, N. S. Ramgir and S. Sivasanker, Appl. Catal., A, 2006, 297, 220-230.

11 H. Shirai, A. Maruyama, K. Kobayashi, N. Hojo and K. Urushido, J. Polym. Sci., Polym. Lett. Ed., 1979, 17, 661-666.

12 M. Kimura, T. Nishigaki, T. Koyama, K. Hanabusa and H. Shirai, Macromol. Chem. Phys., 1994, 195, 3499-3508.

13 N. B. McKeown, S. Makhseed and P. M. Budd, Chem. Commun., 2002, 2780-2781.

14 N. B. McKeown, S. Hanif, K. Msayib, C. E. Tattershall and P. M. Budd, Chem. Commun., 2002, 2782-2783.

15 D. H. Everett, Pure Appl. Chem., 1972, 31, 577-638.

16 A. V. Maffei, P. M. Budd and N. B. McKeown, Langmuir, 2006, 22, 4225-4229

17 P. M. Budd, B. S. Ghanem, S. Makhseed, N. B. McKeown, K. J. Msayib and C. E. Tattershall, Chem. Commun., 2004, 230-231.

18 P. M. Budd, E. S. Elabas, B. S. Ghanem, S. Makhseed, N. B. McKeown, K. J. Msayib, C. E. Tattershall and D. Wang, Adv. Mater., 2004, 16, 456-459.

19 P. M. Budd, N. B. McKeown and D. Fritsch, J. Mater. Chem., 2005, 15, 1977-1986.

20 N. B. McKeown, P. M. Budd, K. J. Msayib, B. S. Ghanem, H. J. Kingston, C. E. Tattershall, S. Makhseed, K. J. Reynolds and D. Fritsch, Chem.-Eur. J., 2005, 11, 2610-2620.

21 N. B. McKeown, B. Gahnem, K. J. Msayib, P. M. Budd, C. E. Tattershall, K. Mahmood, S. Tan, D. Book, H. W. Langmi and A. Walton, Angew. Chem., Int. Ed., 2006, 45, 1804-1807.

22 N. B. McKeown and P. M. Budd, Chem. Soc. Rev., 2006, 35, 675-683.

23 N. B. McKeown, P. M. Budd and D. Book, Macromol. Rapid Commun., 2007, 28, 995-1002.

24 A. H. Cook, J. Chem. Soc., 1938, 1761-1768.

25 H. Shirai, A. Maruyama, J. Takano, K. Kobayashi, N. Hojo and K. Urushido, Makromol. Chem., 1980, 181, 565-573.

26 N. Sehlotho and T. Nyokong, J. Mol. Catal. A: Chem., 2004, 209, 51-57.

27 L. Weber, M. Grosche, H. Hennig and G. Haufe, J. Mol. Catal., 1993, 78, L9-L13.

28 J. E. Baeckvall, R. B. Hopkins, H. Grennberg, M. M. Mader and A. K. Awasthi, J. Am. Chem. Soc., 1990, 112, 5160-5166.

29 A. Zsigmond, F. Notheisz and J.-E. Backvall, Catal. Lett., 2000, 65, 135-139. 